\title{
Percutaneous Transcatheter Balloon Valvuloplasty for Bioprosthetic Tricuspid Valve Stenosis in a Patient with Adult Congenital Heart Dis- ease: A Case Report

\author{
Manabu Nitta*, Teruyasu Sugano, Yusuke Matsumoto, Tomoaki Ishigami, Toshi- \\ yuki Ishikawa, Kochi Tamura
}

Department of Medical Science and Cardiorenal Medicine, Yokohama City University Graduate School of Medicine, Japan

*Corresponding author: Manabu Nitta, Department of Medical Science and Cardiorenal Medicine, Yokohama City University Graduate School of Medicine, 3-9, Fukuura, Kanazawa, Yokohama, 236-0004, Japan, Tel: +81-45-787-2635, Fax: +81-45-701-3738

\begin{abstract}
A 38-year-old male with previous surgeries for an incomplete atrioventricular septal defect successfully underwent percutaneous transcatheter tricuspid balloon valvuloplasty for a deteriorated bioprosthetic valve. Our case highlights the imperative of considering catheter-based minimally invasive therapy for the increasing number of adults with congenital heart disease who may present multiple risks factors for surgery.

Because of advancements in medical and surgical treatment, there has been a decline in mortality from congenital heart defects over the past several decades [1]. As a result, the number of patients with adult congenital heart disease has increased over time [2,3]. Most patients with adult congenital heart disease underwent several surgeries during childhood. In some cases, surgical or catheter interventional treatment in adulthood is recommended because of sequelae or remote-term complications [4,5]. In some cases, catheter intervention is preferable to surgery because the patient is considered a high-risk candidate. In our report, we describe the first case of percutaneous transcatheter bioprosthetic tricuspid balloon valvuloplasty for a patient with adult congenital heart disease.
\end{abstract}

\section{Keywords}

Adult congenital heart disease, Structural valve deterioration, Percutaneous transcatheter tricuspid balloon valvuloplasty

\section{Case Report}

A 38-year-old male presented with right-side heart failure, with symptoms that included dyspnea on exertion, leg edema, and pleural effusion. Soon after birth, he had been diagnosed with incomplete atrioventricular septal defect. At two years of age, a surgical primum atrial septal defect closure, mitral valve plasty, and tricuspid valve plasty were performed. Because he developed severe tricuspid regurgitation at the age of five, a tricuspid valve replacement with a mechanical prosthetic valve (SJM27 mm) was performed. At the age of 20, stuck-valve and severe tricuspid stenosis occurred, and he underwent a second tricuspid valve replacement with a bioprosthetic valve (CEP27 mm). During surgery, an expansive pannus was observed. At the age of 29, the patient ceased medical follow-up. On admission, his physical examination revealed moderate edema in both legs. A Levine Grade III/VI, diastolic rumble also was auscultated at the lower left sternal border. A transthoracic echocardiogram revealed severely calcified, thickened, and immobile leaflets of the bioprosthetic tricuspid valve (Figure 1A, Movie 1). The peak velocity was $2.5 \mathrm{~m} / \mathrm{sec}$ with a mean diastolic gradient across the tricuspid valve of $14 \mathrm{mmHg}$ (Figure 1B). Tricuspid regurgitation was mild. An invasive hemodynamic study by cardiac catheterization revealed $9.8 \mathrm{mmHg}$ of mean transvalvular pressure gradient and mean right atrial pressure that had elevated to $17 \mathrm{mmHg}$. The tricuspid valve area was measured as $1.0 \mathrm{~cm}^{2}$ by Gorlin's equation (Figure 2A). He also had two major comorbidities.

Citation: Nitta M, Sugano T, Matsumoto Y, Ishigami T, Ishikawa T, et al. (2018) Percutaneous Transcatheter Balloon Valvuloplasty for Bioprosthetic Tricuspid Valve Stenosis in a Patient with Adult Congenital Heart Disease: A Case Report. Int J Clin Cardiol 5:125. doi.org/10.23937/2378-2951/1410125 Accepted: October 09, 2018; Published: October 11, 2018

Copyright: (C) 2018 Nitta M, et al. This is an open-access article distributed under the terms of the Creative Commons Attribution License, which permits unrestricted use, distribution, and reproduction in any medium, provided the original author and source are credited. 


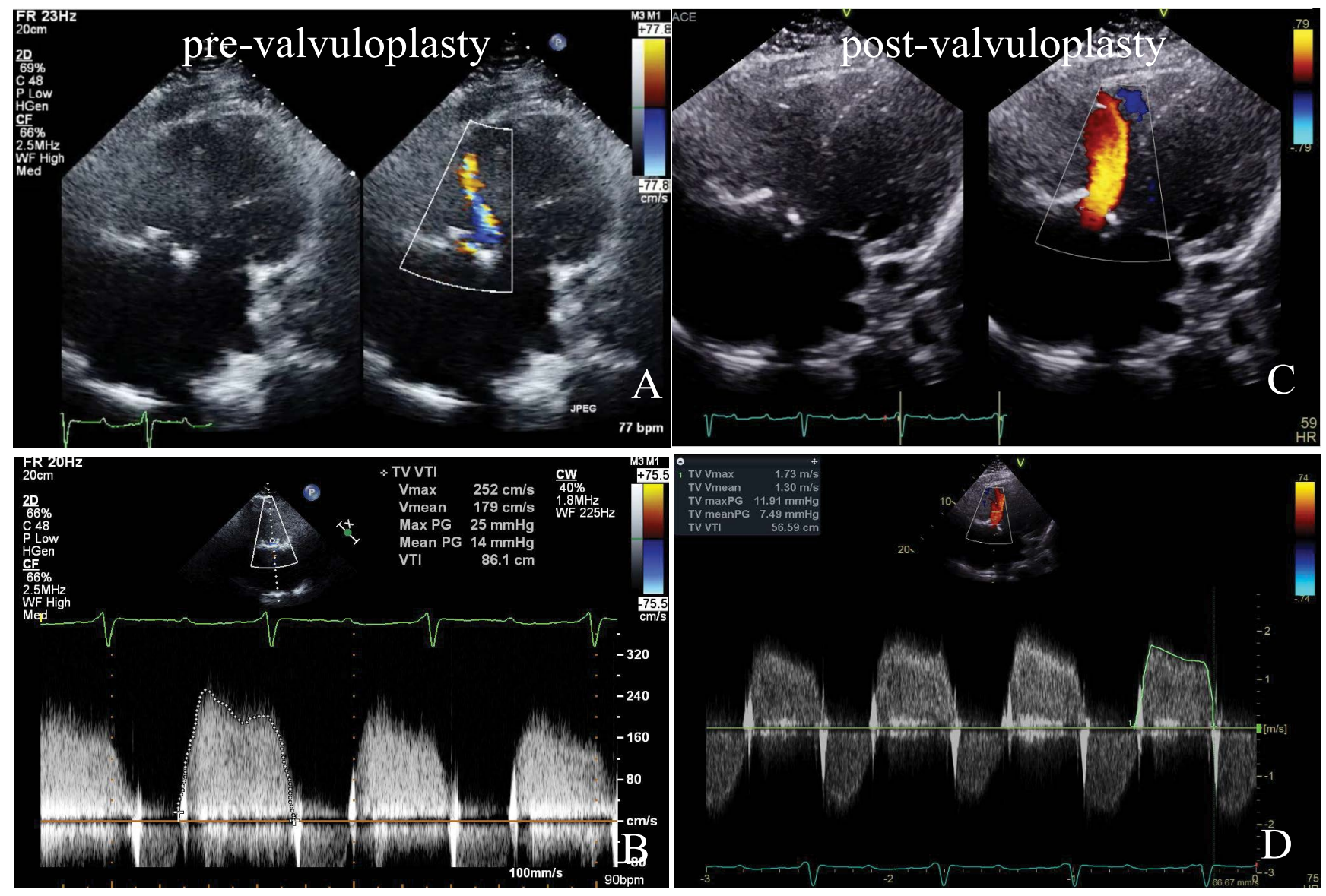

Figure 1: A) Before balloon valvuloplasty, a color Doppler image in the apical four-chamber view shows the narrow tricuspid inflow jet during diastole; B) Before the procedure, peak velocity was $2.5 \mathrm{~m} / \mathrm{sec}$ and the mean pressure gradient across the tricuspid valve was $14 \mathrm{mmHg}$, suggesting tricuspid stenosis; C) After the procedure, tricuspid stenosis improved. The color jet of the tricuspid inflow widened. No significant tricuspid regurgitation occurred; D) After the procedure, peak velocity decreased from $2.5 \mathrm{~m} / \mathrm{sec}$ to $1.7 \mathrm{~m} / \mathrm{sec}$ and the mean pressure gradient across the tricuspid valve decreased from $14 \mathrm{mmHg}$ to $7.5 \mathrm{mmHg}$.

\section{pre-valvuloplasty}

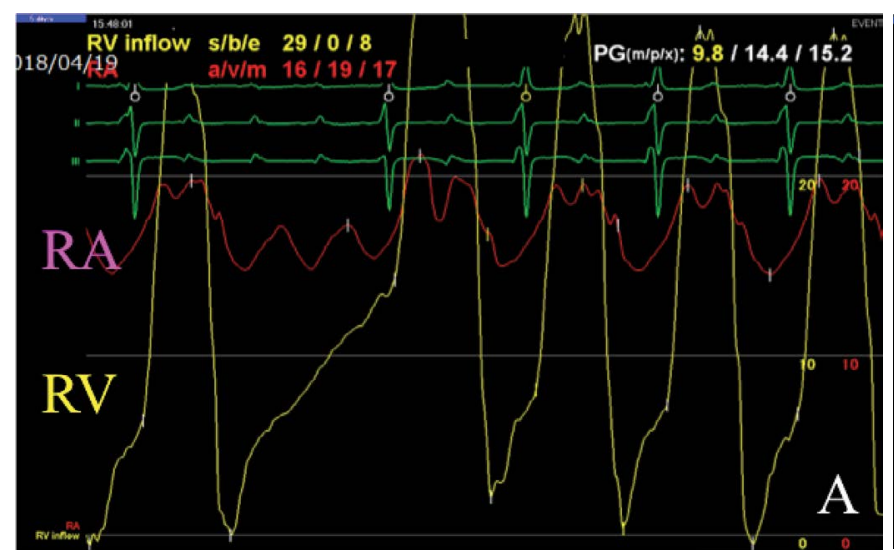

post-valvuloplasty

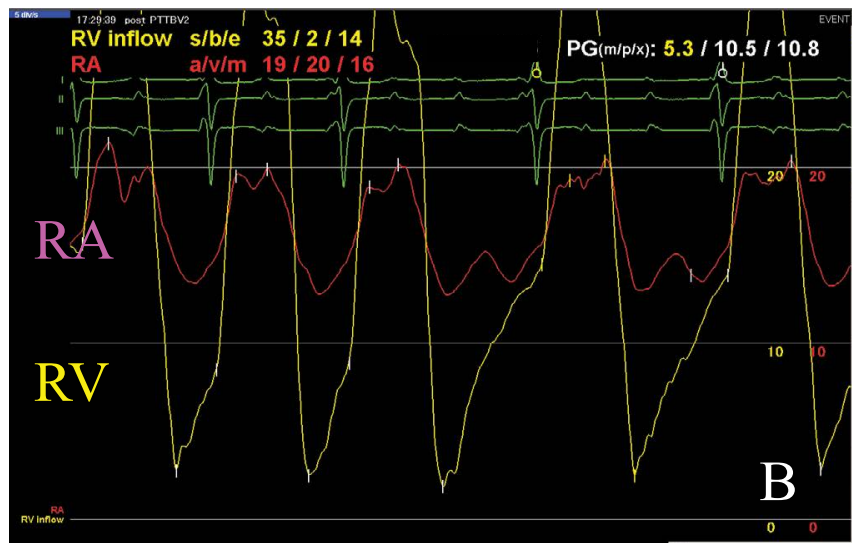

Figure 2: A) Cardiac catheterization revealed $9.8 \mathrm{mmHg}$ of mean transvalvular pressure gradient and mean right atrial pressure that had elevated to $17 \mathrm{mmHg}$. The tricuspid valve area was measured as $1.0 \mathrm{~cm}^{2}$ by Gorlin's equation; B) After the procedure, mean transvalvular pressure gradient decreased to $5.3 \mathrm{mmHg}$, mean right atrial pressure was then reduced to 15 $\mathrm{mmHg}$ and the tricuspid valve area increased to $1.3 \mathrm{~cm}^{2}$.

The first was hepatic cirrhosis due to the hepatitis $B$ virus and a congestive liver; the second was a progressive post-mediastinum tumor, the size of which was $50 \times 55$ $\mathrm{mm}$. His fourth sternotomy was considered a high-risk procedure. His hepatic function also was thought to be insufficient for highly-invasive surgery. Therefore, the patient was offered a percutaneous transcatheter tricuspid balloon valvuloplasty, a less-invasive procedure.

A 14-Fr long sheath was inserted via the right femoral vein and the guide wire passed through the bioprosthesis to the right pulmonary artery. A $26 \mathrm{~mm}$ Inoue balloon (Toray Medical Ltd., Japan) was inflated to a maximum 

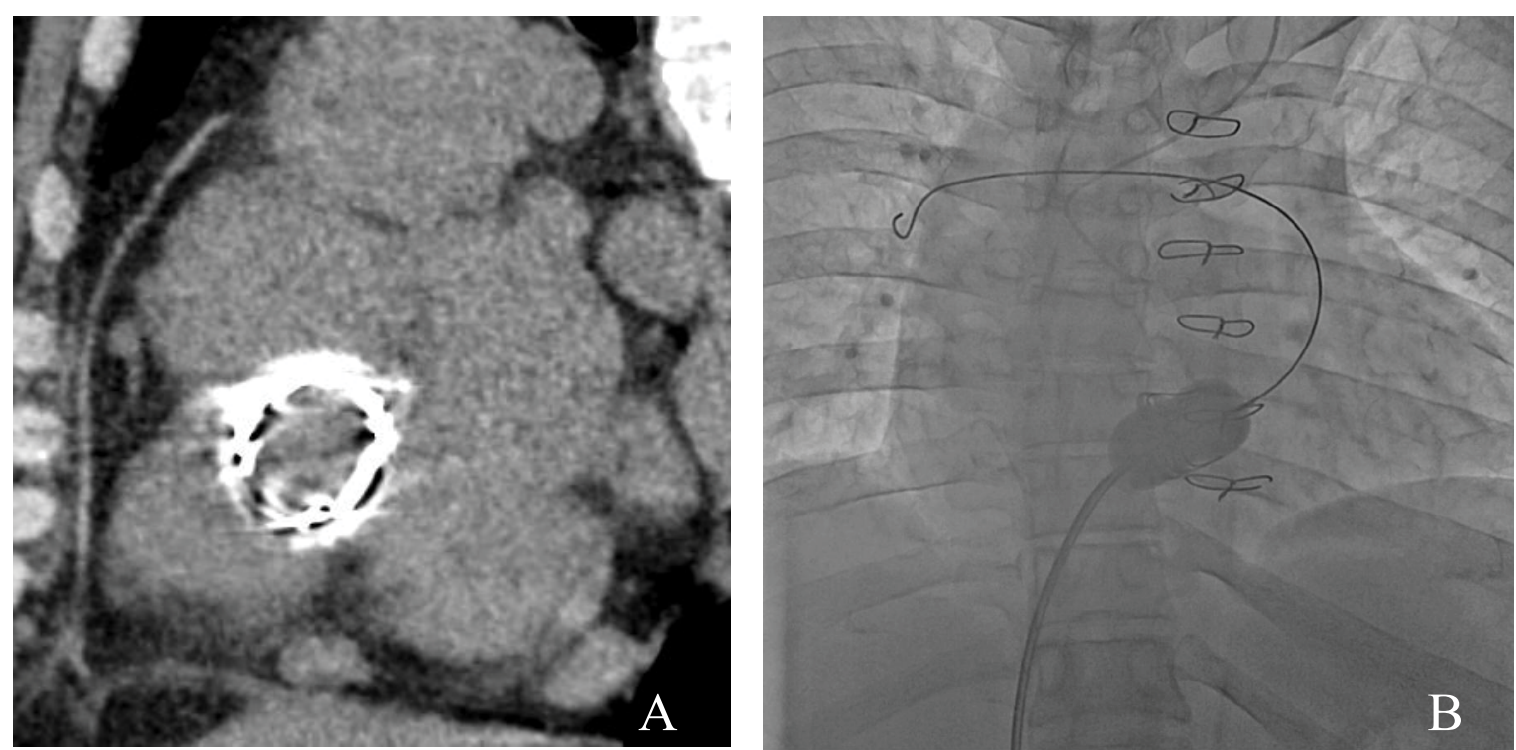

Figure 3: A) CT image before the valvuloplasty shows a highly calcified bioprosthetic valve in the tricuspid position; B) Fluoroscopic image in the anterior-posterior view shows the stiff guide wire passing through the center of the deteriorated bioprosthetic tricuspid valve, with the wire tip in the right pulmonary artery. A balloon valvuloplasty was performed using an Inoue balloon (maximum diameter $26 \mathrm{~mm}$ ).

of $26 \mathrm{~mm}$, equivalent to $96 \%$ of the bioprosthetic valve (Figure $3 \mathrm{~A}$ and Figure $3 \mathrm{~B}$ ). After the procedure, mean transvalvular pressure gradient decreased to $5.3 \mathrm{mmHg}$, mean right atrial pressure was then reduced to 15 $\mathrm{mmHg}$ and the tricuspid valve area increased to $1.3 \mathrm{~cm}^{2}$ (Figure 2B). The echocardiogram revealed that peak velocity had decreased to $1.7 \mathrm{~m} / \mathrm{sec}$, with a mean diastolic gradient of $7.5 \mathrm{mmHg}$ (Figures $1 \mathrm{C}$ and Figure 1D, Movie 2). Deterioration of tricuspid regurgitation did not occur.

The patient's symptoms immediately improved. At six months postoperative, no recurrence of bioprosthetic tricuspid stenosis was reported. Thereafter, resection surgery on the large, post-mediastinum tumor was successfully performed via a left thoracotomy without any complications.

\section{Discussion}

Severe tricuspid valve stenosis is associated with a mean gradient across the tricuspid valve of at least 5 $\mathrm{mmHg}$, a calculated TV area of less than $1.0 \mathrm{~cm}^{2}$ or both $[6,7]$. Because of insufficient data, a percutaneous transcatheter tricuspid balloon valvuloplasty is less preferable to a tricuspid valve replacement. However in some situations, a tricuspid balloon valvuloplasty can be a useful treatment option, especially in patients considered to be a higher surgical risk. In general, a history of prior cardiac surgeries in an adult with congenital heart disease makes repeat surgery difficult because of adhesions, excessive bleeding, and other factors [8]. In our case, a fourth sternotomy and on-pump surgery seemed too invasive.

Feit and colleagues first reported on percutaneous transcatheter tricuspid balloon valvuloplasty in 1986 [9]. Rana and colleagues reviewed case reports of this type of transcatheter intervention, excluding the native tricuspid valve, that were published in journals from 1980 through 2017 [10]. In their review of 15 articles, 19 cases were identified and in 18 of these 19 cases (95\%), the authors reported a successful reduction of the transvalvular pressure gradient. The mean pre-procedural pressure gradient was $12 \mathrm{mmHg}$ and the post-procedural gradient improved to an average mean residual of $7 \mathrm{mmHg}$. There were no major procedure-related adverse events reported. In most cases, underlying cardiac disease was involved, such as rheumatic fever or infectious endocarditis. Wren and colleagues reported on a congenital heart disease case involving a minor-age patient [11]. No one reported on a case of adult congenital heart disease.

It remains unclear how long a bioprosthetic tricuspid valvuloplasty is effective. In general, the durability of a prosthetic valve in the aortic or mitral position is thought to be 10 or 20 years [12]. The durability of a prosthesis in the tricuspid position is less-known. A mechanical valve in the tricuspid position is known to be at a 20-times higher risk for valve thrombosis than in the aortic or mitral position [13]. When our patient undergoes a third bioprosthetic valve replacement, he will still need more valve replacement surgeries in the future. A balloon valvuloplasty is less invasive and can be repeatedly used as a palliative option, which may reduce the total number of valve replacement and sternotomy procedures. As a final point, the transcatheter implantation of a valve-in-valve for a failed tricuspid bioprosthesis might prove to be an appropriate option for highly select patients [14]. However durability remains unknown. To the best of our knowledge, this is the first case report of a percutaneous transacatheter balloon valvuloplasty for bioprosthetic tricuspid valve stenosis in a patient with adult congenital heart disease.

\section{Conclusion}

A percutaneous transcatheter tricuspid balloon 
valvuloplasty can be an alternative option to surgical tricuspid valve replacement, especially in high-risk patients. Certain patients with adult congenital heart disease will be suitable for this procedure.

\section{Acknowledgements}

None.

\section{Financial Support}

This report received no specific grant from any funding agency, commercial or not-for-profit entity.

\section{Conflict of Interest}

The authors have no conflict of interest to disclose.

\section{Ethical Standards}

The patient provided informed consent for publication.

\section{Disclosure}

The authors have no conflicts of interest to disclose.

\section{References}

1. Gilboa SM, Salemi JL, Nembhard WN, Fixler DE, Correa A (2010) Mortality resulting from congenital heart disease among children and adults in the United States, 1999 to 2006. Circulation 122: 2254-2263.

2. Shiina $Y$, Toyoda $T$, Kawasoe $Y$, Tateno S, Shirai $T$, et al (2011) Prevalence of adult patients with congenital heart disease in Japan. Int Journal of Cardiol 146: 13-16.

3. Gilboa SM, Devine OJ, Kucik JE, Oster ME, Riehle-Colarusso T, et al. (2016) Congenital heart defects in the United States estimating the magnitude of the affected population in 2010. Circulation 134: 101-109.

4. Bhatt AB, Foster E, Kuehl K, Alpert J, Brabeck S, et al (2015) Congenital heart disease in the older adult: A scien- tific statement from the American Heart Association. Circulation 13: 1884-1931.

5. Perloff JK (1983) Adults with surgically treated congenital heart disease. Sequelae and residua. JAMA 250: 2033-2036.

6. Nishimura RA, Otto CM, Bonow RO, Carabello BA, Erwin JP 3rd, et al. (2014) 2014AHA/ACC guideline for the management of patients with valvular heart disease: A report of the American College of Cardiology/American Heart Association Task Force on Practice Guidelines. J Am Coll Cardiol 63: e57-e185.

7. Baumgartner H, Falk V, Bax JJ, De Bonis M, Hamm C, et al. (2017) 2017 ESC/EACTS Guidelines for the management of valvular heart disease. Eur Heart J 38: 2739-2791.

8. Laks H, Marelli D, Plunkett M (2007) Adult Congenital Heart Disease. In: Cohn LH, Cardiac Surgery in the Adult. ( $3^{\text {rd }}$ edn), Mc Graw-Hill company, 1431-1464.

9. Feit F, Stecy PJ, Nachamie MS (1986) Percutaneous balloon valvuloplasty for stenosis of a porcine bioprosthesis in the tricuspid valve position. Am J Cardiol 58: 363-364.

10. Rana G, Malhotra R, Sharma A, Nikolaos Kakouros (2017) Percutaneous valvuloplasty for bioprosthetic tricuspid valve stenosis. Tex Heart Inst J 44: 43-49.

11. Wren C, Hunter S (1989) Balloon dilatation of a stenosed bioprosthesis in the tricuspid valve position. Br Heart J 61: 65-67.

12. Hammermeister KE, Henderson WG, Burchfiel CM, Sethi GK, Souchek J, et al. (1987) Comparison of outcome after valve replacement with a bioprosthesis versus a mechanical prosthesis: Initial 5-year results of a ran- domized trial. J Am Coll Cardiol 10: 719-732.

13. Roudaut R, Serri K, Lafitte S (2007) Thrombosis of prosthetic heart valves: Diagnosis and therapeutic considerations. Heart 93: 137-142.

14. Daneault B, Williams MR, Leon MB, Paradis JM, Kodali SK (2013) Transcatheter tricuspid valve-in-valve replacement resulting in 4 different prosthetic heart valves in a single patient. J Am Coll Cardiol 61: e3. 